\title{
Estudio in vitro del Efecto Antibacteriano de la Oleorresina de Copaifera reticulata y el Aceite Esencial de Origanum majoricum Frente a Streptococcus mutans y Enterococcus Faecalis Bacterias de Importancia en Patologías Orales
}

\author{
In vitro Study of the Antibacterial Effect of Oleoresin of Copaifera reticulata \\ and the Essential Oil of Origanum majoricum against Streptococcus mutans \\ and Enterococcus faecalis Bacteria of Importance in Oral Pathologies
}

\begin{abstract}
Hilda Moromi Nakata1,2; Donald Ramos Perfecto ${ }^{1,2}$; Jorge Villavicencio Gastelumendi,3; Elba Martínez Cadillo ${ }^{1,2}$; Alejandro Mendoza Rojas 1,2; Edith Chavez Alvarado1; Lita Ortiz Fernández ${ }^{1,4}$ \& Ángela Quispe Salcedo ${ }^{1,2}$
\end{abstract}

MOROMI , N. H.; RAMOS, P. D.; VILLAVICENCIO, G. D.; MARTÍNEZ, C. E.; MENDOZA, R. A.; CHAVEZ, A. E.; ORTIZ, F L. \& QUISPE, S. Á. Estudio in vitro del efecto antibacteriano de la oleorresina de Copaifera reticulata y el aceite esencial de origanum majoricum frente a Streptococcus mutans y Enterococcus faecalis bacterias de importancia en patologías orales. Int. J. Odontostomat., 12(4):355-361, 2018.

RESUMEN: El objetivo del estudio fue determinar el efecto antibacteriano in vitro de la oleorresina de Copaifera reticulata (C. reticulata) "copaiba" y del aceite esencial de Oreganum majoricum (O. majoricum) "orégano" frente a Streptococcus mutans (S. mutans) y Enterococcus faecalis (E. faecalis). Se desarrollaron pruebas de sensibilidad activando primero las cepas bacterias a enfrentar. La oleorresina de copaiba fue diluida con dimetilsulfósido (DMSO), obteniéndose al final concentraciones a probar de $100 \%, 50 \%, 25 \%$, y 12,5\%. En relación al aceite esencial de orégano este se probó solamente al $100 \%$. Para la prueba de difusión en agar con discos, se tomaron inóculos $100 \mu \mathrm{L}$ de cada cepa bacteriana a una turbidez de 0,5 de Mc Farlam, para ser sembrados por diseminación en placas de tripticasa soya agar, para luego colocar los discos de forma equidistante cargados con las diferentes concentraciones de los productos naturales, se utilizaron como control positivo a la clorhexidina al 0,12 \% y al DMSO como control negativo. Se incubaron las placas por el método de la vela en extinción a $37^{\circ} \mathrm{C}$, por un periodo de 24 horas, pasado el tiempo se realizó la lectura de los halos de inhibición. Los resultados obtenidos por la copaiba, determinaron un efecto antibacteriano en sus cuatro concentraciones, siendo los mayores halos de inhibición a la concentración del $100 \%$, copaiba genero mayores halos promedios para $S$, mutans de 30,00 $\pm 0,00 \mathrm{~mm}$ y para $E$. faecalis de 8,3 $\pm 0,50 \mathrm{~mm}$. Para el caso del orégano se producen halos a la concentración del $100 \%$ con un promedio de 25,3 \pm 0,96 mm para $S$. mutans y para $E$. faecalis de $9,5 \pm 1,29 \mathrm{~mm}$. Se concluye del estudio que tanto copaiba como el orégano presentan un efecto antibacteriano para ambas bacterias, siendo su mayor efecto antibacteriano para ambos productos naturales sobre S. mutans. mutans.

PALABRAS CLAVE: agente antibacteriano, Enterococcus faecalis, copaiba, orégano, Streptococcus

\section{INTRODUCCIÓN}

El Perú es reconocido por su biodiversidad, por tanto los esfuerzos por identificar plantas con principios activos que pueden servir como alternativas para mejorar las condiciones de patologías orales.
Se menciona que las plantas pueden ser un sustituto de la medicina convencional de una manera más efectiva de costo beneficio y es de interés para los investigadores en la odontología por su alto poten-

\footnotetext{
${ }^{1}$ Universidad Nacional Mayor de San Marcos (UNMSM), Perú.

2 Docente del Departamento Académico de Ciencias Básicas Facultad de Odontología UNMSM, Perú.

${ }^{3}$ Docente del Departamento Académico de Estomatología Médico Quirúrgico Facultad de Odontología UNMSM, Perú.

${ }^{4}$ Docente del Departamento Académico de Odontología Preventiva y Social UNMSM, Perú.
} 
MOROMI , N. H.; RAMOS, P. D.; VILLAVICENCIO, G. D.; MARTínEZ, C. E.; MENDOZA, R. A.; CHAVEZ, A. E.; ORTIZ, F L. \& QUISPE, S. Á. Estudio in vitro del efecto antibacteriano de la oleorresina de Copaifera reticulata y el aceite esencial de origanum majoricum frente a Streptococcus mutans y Enterococcus faecalis bacterias de importancia en patologías orales. Int. J. Odontostomat., 12(4):355-361, 2018.

cial terapéutico (Alvares \& Alvares Junior, 2009). El Perú es considerado el tercer país más diverso del mundo, efectuando importantes aportes con su flora natural al orbe, gracias a los diversos pisos ecológicos y microclimas que presenta, contando con 84 zonas de vida de las 103 conocidas donde habría 50 mil especies vegetales, $20 \%$ de las existentes en la tierra, de las que 2000 han sido utilizadas con fines curativos (Pereyra, 2009).

Los aceites esenciales como del Origanum majoricum "oregano" son productos obtenidos de diferentes partes de las plantas como hojas, flores, frutos, raíces, se consideran productos secundarios del metabolismo (Madsen \& Bertelsen, 1995; Burt, 2007; Bandoni et al., 2009; Acevedo et al., 2013; Koo \& Jeon, 2009; Kunze et al., 2010).

En cambio, la oleorresina de Copaifera es sintetizada por células parenquimáticas, localizada en toda las partes del árbol (Herrero, 2010) es un líquido transparente con viscosidad y color variable compuesto por sesquiterpenes y diterpenes (Veiga Junior \& Pinto, 2002). En la Medicina folklórica tradicional este producto es utilizado como antiinflamatorio (Veiga Junior et al., 2001) antimicrobiano (Pacheco et al., 2014), antileishmaniasico (Dos Santos et al., 2012), cicatrizante (Arroyo-Acevedo et al., 2011), antitumoral (Lima et al., 2003), y en diferentes enfermedades (Leandro et al., 2012), como gonorrea, sífilis, cistitis, faringitis, neumonía, sinusitis, dermatitis, reumatismo, herpes, leishmaniasis, tumor de próstata entre otros.

Por otro lado, el orégano es una herbácea con propiedades aromáticas, utilizado en la alimentación y medicinalmente (Arcila-Lozano et al., 2004). Se reportan varias propiedades como la antibacteriana, antifúngica, antioxidante, igualmente se han hecho estudio sobre su accionar como preservarte de alimentos del aceite esencial (Tavares, 2014). El aceite esencial de orégano es un producto derivado de la destilación por arrastre con vapor de agua, los efectos de sus propiedades, se deben a la presencia de compuestos fenólicos como timol, carvacrol principalmente (Arcila-Lozano et al.).

El objetivo del estudio fue determinar el efecto antibacteriano in vitro de la oleorresina de copaiba y el aceite esencial de orégano frente a las cepas de E.faecalis y S.mutans, bacterias de relevancia en las patologías orales.

\section{MATERIAL Y MÉTODO}

El presente estudio de tipo experimental, in vitro, prospectivo, transversal, se desarrolló haciendo uso de la oleorresina de copaiba obtenido en la región de Iquitos-Perú y del aceite esencial del orégano obtenido en la Facultad de Farmacia y Bioquímica de la Universidad Nacional Mayor de San Marcos (UNMSM), Perú. El estudio tuvo un proceso de revisión en su metodología y ejecución por el Instituto de Investigación de la Facultad de Odontología de la Universidad Nacional Mayor de San Marcos, Perú.

Oleorresina de copaiba. El método de extracción de la oleorresina fue por perforación del árbol, el cual se realizó con un Barreto, instrumento tipo sacacorchos, que llega a perforar hasta la mitad del diámetro del árbol. La recolección se llevó en una reserva natural de la ciudad de lquitos, región Loreto. La identificación de la planta fue realizada, por el herbario amazonense de la Facultad de Biología de la Universidad Nacional de la Amazonia Peruana (UNAP), Perú.

Aceite esencial del orégano. El aceite esencial del orégano se obtuvo a partir de plantas de Origanum majoricum (O.majoricum), recolectadas en el distrito de Tiabaya, Arequipa, se transportó al laboratorio de La Facultad de Farmacia y Bioquímica de la UNMSM en estado semideshidratadas. El proceso de extracción del aceite esencial se realizó utilizando hojas y flores de la planta; con la técnica de destilación por arrastre con vapor de agua en un equipo de 10 litros. Las condiciones de operación del equipo de extracción fueron: tiempo tres horas, densidad de lecho $200 \mathrm{~g} / \mathrm{L}$ y presión de vapor $0,32 \mathrm{psi}$ recolectándose el aceite en un vaso florentino para su decantado y deshidratación con sulfato de sodio anhidro $\left(\mathrm{SO}_{4} \mathrm{Na}_{2}\right)$. Se obtuvo un rendimiento promedio de $19,0 \mathrm{~mL}$ de aceite/Kg de hojas y flores semideshidratadas.

Cepas bacterianas. Las cepas de S. mutans ATCC 25175 y E. faecalis ATCCC 29212, fueron reactivadas en medio de tripticasa soya agar (TSA) por 24 horas a $37^{\circ} \mathrm{C}$ en condiciones de anaerobiosis parcial y aerobiosis respectivamente.

Prueba de sensibilidad bacteriana. Para el estudio sobre el efecto antibacteriano de las diferentes concentraciones, tanto de la oleorresina de copaiba y del aceite esencial del orégano, se utilizó el méto- 
do de difusión en agar con discos. Se utilizaron ocho placas de TSA que fueron sembradas por diseminación con un inóculo de $100 \mu \mathrm{l}$ con un nivel de turbidez del 0,5 de Mc Farlam, cuatro para E. faecalis y cuatro para S. mutans, los discos fueron cargados con las concentraciones de $100 \%, 50 \%, 25 \%$ y $12,5 \%$ y colocados equidistantemente en TSA, así también se colocaron dos discos uno como control positivo que fue de clorhexidina y otro de control negativo que fue el dimetilsulfoxido (DMSO), las placas fueron incubadas a $37^{\circ} \mathrm{C}$ en condiciones de aerobiosis para $E$. faecalis y anaerobiosis parcial (método de la vela en extinción) para S. mutans por 24 horas.

Para el caso del orégano, la concentración utilizada fue del $100 \%$ de Orégano $(9,234 \mu \mathrm{g} / \mathrm{mL})$ y que igualmente fue utilizado como control negativo al DMSO y Como control positivo se utilizó Clorhexidina al $0,12 \%$, la prueba fue la misma que se desarrolló con copaiba.

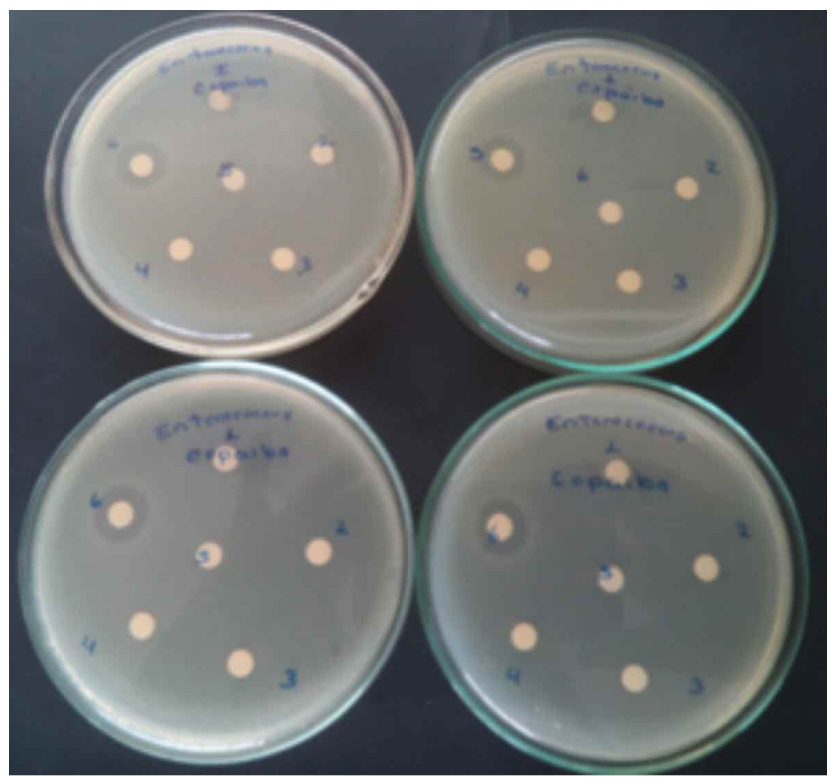

Fig. 1. Efecto de la oleorresina de Copaiba frente a $E$. faecalis en TSA. 1 (100\%), 2 (50\%), $3(25 \%), 4(12,5 \%), 5$ (DMSO), 6 (Clorhexidina $0,12 \%)$.

\section{RESULTADO}

En la Tabla I y Figura 1, se muestra el efecto de la oleorresina de Copaiba frente a la cepa de $E$. faecalis, de acuerdo a cuatro concentraciones de 100 $\%, 50 \%, 25 \%$ y $12,5 \%$, observándose mayor efecto al $100 \%$ disminuyendo su acción cuanto menor es la concentración.

En el caso de la acción de la oleorresina de Copaiba sobre la cepa de $S$. mutans, se observa en la Tabla Il y Figura 2, que la concentración de $100 \%$ tiene mayor acción que las demás concentraciones, mayor incluso que la clorhexidina, disminuyendo igualmente su acción en cuanto hay mayor dilución del producto.

La acción de la oleorresina de Copaiba es mucho mayor sobre S. mutans que sobre E. faecalis. Tablas III y IV.

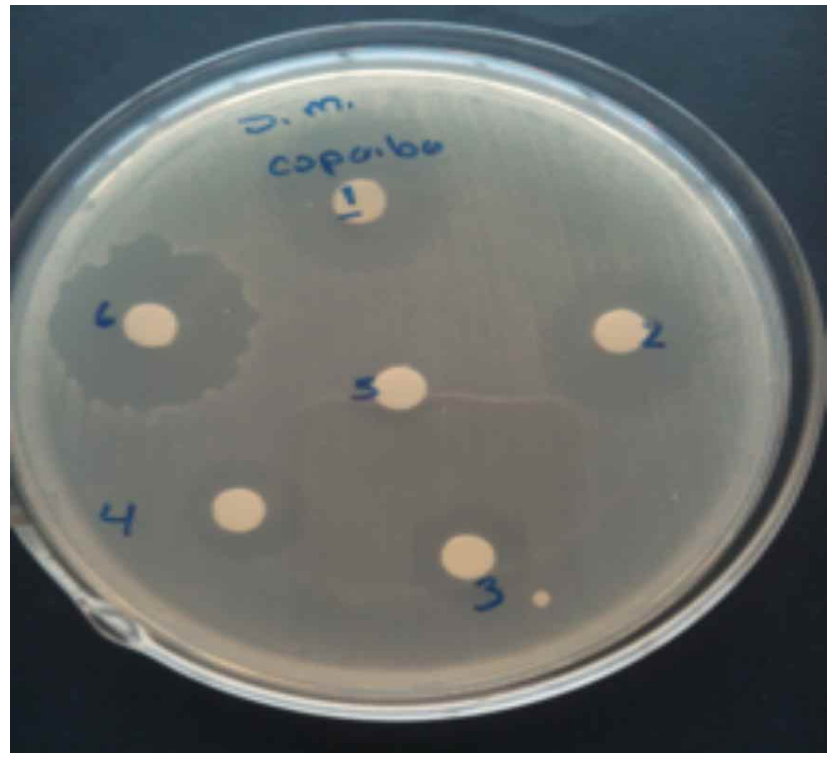

Fig. 2. Efecto dela Oleorresina de Copaiba Frente a $S$. mutans en TSA 1 (100\%), 2 (50\%), 3 (25\%), 4 (12,5\%), 5 (DMSO), 6 (Clorhexidina 0,12\%).

Tabla I. Efecto de la oleorresina de Copaiba frente a cepa de E. faecalis según concentración.

\begin{tabular}{ccccccc}
\hline & \multicolumn{7}{c}{ COPAIBA } \\
Placa & $100 \%$ & $50 \%$ & $25 \%$ & $12,50 \%$ & Clorhexidina & DMSO \\
\hline 1 & 9 & 8 & 8 & 7 & 14 & 6 \\
2 & 8 & 8 & 8 & 7 & 13 & 6 \\
3 & 8 & 8 & 8 & 7 & 14 & 6 \\
4 & 8 & 8 & 8 & 7 & 13 & $6 \pm 0,0$ \\
\hline
\end{tabular}

Diámetro de halos de inhibición (mm). 
MOROMI , N. H.; RAMOS, P. D.; VILLAVICENCIO, G. D.; MARTíNEZ, C. E.; MENDOZA, R. A.; CHAVEZ, A. E.; ORTIZ, F L. \& QUISPE, S. Á. Estudio in vitro del efecto antibacteriano de la oleorresina de Copaifera reticulata y el aceite esencial de origanum majoricum frente a Streptococcus mutans y Enterococcus faecalis bacterias de importancia en patologías orales. Int. J. Odontostomat., 12(4):355-361, 2018.

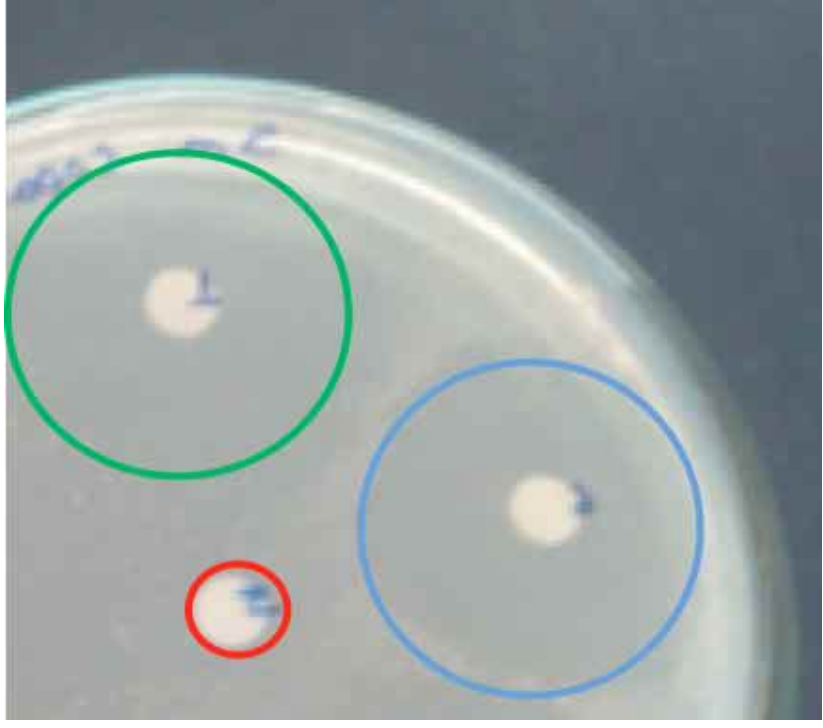

Fig. 3. Círculo verde orégano al $100 \%$, círculo azul Clorhexidina al $0,12 \%$ y círculo rojo DMSO.

\section{DISCUSIÓN}

Diversas investigaciones han demostrado el efecto antimicrobiano de la oleorresina de Copaifera, frente a bacterias así como a hongos, de acuerdo a diversas metodologías utilizadas. En el estudio desarrollado se ha evaluado el efecto antibacteriano in vitro mediante el método de difusión en agar con discos, el efecto de la oleorresina frente a dos cepas de importancia relacionadas con patologias orales como son el $S$. mutans en el caso de la caries dental y $E$. faecalis en procesos endodónticos. Las concentraciones fueron al $100 \%, 50$ $\%, 25 \%$ y $12,5 \%$ con diferencias significativas en los promedios de los halos de inhibición directamente proporcional a la concentración, salvo en el casos de las concentraciones de $50 \%$ y $25 \%$ en que presentaron similar acción, siendo la susceptibilidad del S. mutans sumamente superior con respecto al $E$. faecalis.

Masson et al. (2013) evaluaron la actividad

Tabla II. Efecto de la oleorresina de copaiba según concentración frente cepa de S. mutans.

\begin{tabular}{|c|c|c|c|c|c|c|}
\hline \multirow{2}{*}{$\begin{array}{l}\text { S.mutans } \\
\text { Placa }\end{array}$} & \multicolumn{6}{|c|}{ COPAIBA } \\
\hline & $100 \%$ & $50 \%$ & $25 \%$ & $12.50 \%$ & Clorhexidina & DMSO \\
\hline 1 & 30 & 25 & 24 & 22 & 26 & 6 \\
\hline 2 & 30 & 25 & 24 & 22 & 27 & 6 \\
\hline 3 & 30 & 25 & 24 & 24 & 26 & 6 \\
\hline 4 & 30 & 25 & 24 & 24 & 30 & 6 \\
\hline Promedio & $30 \pm 0,0$ & $25 \pm 0,0$ & $24 \pm 0,0$ & $23 \pm 1,15$ & $27,3 \pm 1,89$ & $6 \pm 0,0$ \\
\hline
\end{tabular}

Diámetro de halos de inhibición $(\mathrm{mm})$.

Tabla III. Halos de inhibición del aceite esencial de orégano frente a $E$. faecalis.

Diámetros de halos de inhibición $(\mathrm{mm})$.

\begin{tabular}{cccc}
\hline Placa & orégano $100 \%$ & Clorhexidina & $D M S O$ \\
\hline 1 & 11 & 13 & 6 \\
2 & 10 & 14 & 6 \\
3 & 8 & 12 & 6 \\
4 & 9 & 14 & 6 \\
Promedio & $9,5 \pm 1,29$ & $13,3 \pm 0,96$ & $6 \pm 0,0$ \\
\hline
\end{tabular}

Tabla IV. Halos de inhibición del aceite esencial de orégano frente a $S$. Mutans.

\begin{tabular}{|c|c|c|c|}
\hline Placa & orégano & Clorhexidina & DMSO \\
\hline 1 & 26 & 23 & 6 \\
\hline 2 & 25 & 26 & 6 \\
\hline 3 & 24 & 24 & 6 \\
\hline 4 & 26 & 25 & 6 \\
\hline Promedio & $25,3 \pm 0,96$ & $24,5 \pm 1,29$ & $6 \pm 0,0$ \\
\hline
\end{tabular}


MOROMI , N. H.; RAMOS, P. D.; VILLAVICENCIO, G. D.; MARTíNEZ, C. E.; MENDOZA, R. A.; CHAVEZ, A. E.; ORTIZ, F L. \& QUISPE, S. Á. Estudio in vitro del efecto antibacteriano de la oleorresina de Copaifera reticulata y el aceite esencial de origanum majoricum frente a Streptococcus mutans y Enterococcus faecalis bacterias de importancia en patologías orales. Int. J. Odontostomat., 12(4):355-361, 2018.

antimicrobiana de la oleorresina contra bacterias Gram positivas como Staphylococcus aureus, Streptococcus pyogenes, E. faecalis y bacterias Gram negativas como como Pseudumonas, Escherichia coli, determinando la concentración mínima inhibitoria (CMI) contra $E$. feacalis de $1100 \mu \mathrm{g} / \mathrm{mL}$ con rango de 1,56-2000 $\mu \mathrm{g} /$ $\mathrm{mL}$ y con concentración mínima letal (CML) de 1200 $\mu \mathrm{g} / \mathrm{mL}$ considerando su uso como componente tópico para heridas infectas con bacterias Gram positivas. Estos resultados no concuerdan del todo con los nuestros, ya que si bien hay un efecto inhibitorio del $E$. faecalis por la copaiba, éste tiene un nivel bajo.

Dos Santos et al. estudiaron la actividad antibacteriana y antifúngica de la oleorresina de copaiba (Copaifera martii, C. officinalis, C. reticulata) contra bacterias Gram positivas y Gram negativas, levaduras y dermatofitos donde los resultados muestran que concentraciones mínimas inhibitorias en el rango de 31,3 a $62,5 \mu \mathrm{g} / \mathrm{mL}$, son activas contra Staphylococcus aureus, S. epidermidis, Bacillus subtilis y Enterococos faecalis. Así también, Mendonça \& Onofre (2009) realizaron pruebas de susceptibilidad sobre cepas de Escherichia coli ATCC 25922, Staphylococcus aureus ATCC 25933 y Pseudomonas aeruginosa ATCC 9027 demostrando que la oleorresina de copaiba posee capacidad de inhibir el crecimiento de las tres bacterias evaluadas, a una concentración mínima inhibitoria de 1,56 \% v/v, 3,12\% v/v y $12,5 \% \mathrm{v} / \mathrm{v}$ para cada bacterias respectivamente. También Ramos, determino la acción antibacteriana de la copaiba frente a la Porphyromonas gingivalis, patógeno principal de la periodontitis crónica, obtuvo acción positiva de la oleorresina a las concentraciones de 100 $\%$ v/v y $50 \%$ v/v. Con una concentración mínima inhibitoria de $3,43 \%$ v/v (Ramos \& Castro, 2014). Estos resultados confirman que la oleorresina tiene una gran actividad antibacteriana, similar a lo que pudimos encontrar al enfrentarlo con $S$. mutans que es muy sensible a la copaiba, Bardají et al. (2016) determinaron la caracterización química y propiedades antibacterianas de la Copaifera reticulata contra patógenos orales. Los valores del CMI Y CML variaron entre 6,25 a $200 \mu \mathrm{g} / \mathrm{mL}$ para las bacterias probadas y en los casos de E. faecalis ATCC 4082 fue de $100 \mu \mathrm{g} / \mathrm{mL}$ y $200 \mu \mathrm{g} / \mathrm{mL}$ y para S. mutans ATCC 25175 de $50 \mu \mathrm{g} / \mathrm{mL}$ respectivamente. Concluyendo que la oleorresina de copaiba puede ser utilizada para desarrollar formulaciones en la prevención y tratamiento de la caries dental (Bardají et al.). Resultados similares hemos podido obtener ya que los halos de inhibición de copaiba sobre $S$. mutans dieron como promedio, $30 \mathrm{~mm}$ para la concentración del $100 \%$ determi- nando su gran efecto sobre esta bacteria, sumándonos al desarrollo de una formulación en la prevención o tratamiento de la caries dental.

A pesar de la variabilidad de las técnicas utilizadas en los estudios, las evidencias confirman la capacidad de acción de la oleorresina de copaiba, principalmente frente a los microorganismos Gram positivos, en los casos mencionados frente a bacterias de importancia en procesos orales que se presentan con mayor frecuencia.

En relación al aceite esencial de orégano los resultados obtenidos al enfrentarlo con $E$. faecalis nos muestra que este producto tuvo mejor acción (promedio de $9,8 \mathrm{~mm})$ que la oleorresina de Copaiba $(8,5$ $\mathrm{mm})$. Sin embargo frente al $S$. mutans el resultado de la acción del aceite esencial del orégano evidenció alta efectividad $(24,1 \mathrm{~mm})$ pero menor que la presentada por la oleorresina de copaiba $(29,8 \mathrm{~mm})$ según los promedios de los halos de inhibición.

Benbelaïd et al. (2014) evaluaron, con diferentes aceites esenciales. el tratamiento de infecciones orales, causadas principalmente por el biofilm del Enterococcus faecalis multiresistente a la infección periodontal y tratamientos endodonticos entre ellas el Origanum vulgare subsp. glandulosum (Desf.) fueron evaluados frente a cepas de E. faecalis. ATCC 29212 y ATCC 49452, sensibles a los antibióticos, y obtenidos de pacientes con diferentes enfermedades orales, mediante el método modificado de difusión con disco Kirby-Bauer en agar, los resultados mostraron un diámetro de inhibición para E. faecalis ATCC 29212 de $28 \pm 1 \mathrm{~mm}$ y para E. faecalis ATCC $2921229 \pm 1$ $\mathrm{mm}$, la CMI fue 0,063 $\pm 0,000$ para ambos (Bendalaid et al., 2014).

Mello da Silveira et al. (2012) evaluaron la actividad antimicrobiana de diez aceites esenciales de plantas seleccionadas, entre ellas orégano (Origanum vulgare), presentando actividad antibacteriana a doce cepas, entre ellas al Enterococcus faecalis ATCC 29212. La determinación del efecto inhibitorio de los aceites esenciales sobre las bacterias fue determinada por el método de difusión en disco de papel estéril de $9 \mathrm{~mm}$ de diámetros. Se utilizó como control positivo Ampicilina (10 mg disc-1) y Cloranfenicol (30 mg disc-1). Los diámetros de las zonas de inhibición incluidos el diámetro del disco fueron medidos en milímetros y la inhibición fue determinado: el mínimo (10$13,9 \mathrm{~mm})$, moderado $(14-18 \mathrm{~mm})$ y el alto $(>18 \mathrm{~mm})$. Los resultados muestran un efecto inhibitorio del acei- 
MOROMI , N. H.; RAMOS, P. D.; VILLAVICENCIO, G. D.; MARTíNEZ, C. E.; MENDOZA, R. A.; CHAVEZ, A. E.; ORTIZ, F L. \& QUISPE, S. Á. Estudio in vitro del efecto antibacteriano de la oleorresina de Copaifera reticulata y el aceite esencial de origanum majoricum frente a Streptococcus mutans y Enterococcus faecalis bacterias de importancia en patologías orales. Int. J. Odontostomat., 12(4):355-361, 2018.

te esencial del Orégano contra el Enterococcus faecalis con halos de 16,0 \pm 0,7 mm (Mello da Silveira et al.). En relación a que podría generar el efecto antibacteriano del orégano, Khan et al. (2017) estudiaron los dos componentes principales del orégano, demostrando que el Timol y Cravacrol, evidencian fuerte acción bactericida y antibiofilm, por el método de dilución y conteo de formación de placa.

Si bien los resultados obtenidos en el presente estudio fueron menores comparando con los estudios de Benbelaïd et al. y Mello da Silveira et al., se debe considerar factores como la procedencia del producto, la metodología utilizada, sin embargo en todos los casos se evidenció acción antibacteriana frente a ambas cepas utilizadas.

Del estudio se concluye que la oleorresina de copaiba tuvo mejor efecto antibacteriano que el aceite esencial de orégano frente a la cepa de $S$. mutans a diferencia del orégano que fue más efectivo contra el E. faecalis, El efecto de las diferentes concentraciones de la oleorresina de copaiba no tuvo diferencia significativa frente a $E$. faecalis, a diferencia de la acción sobre el S.mutans en que a mayor concentración tuvo mayor efecto antibacteriano. El desarrollo de estudios estandarizados puede mejorar los conocimientos respectos a estos dos productos naturales que tiene una gran proyección a futuro, como fuente de obtención de una formulación con fines de prevención y tratamiento de patologías orales.

MOROMI , N. H.; RAMOS, P. D.; VILLAVICENCIO, G. D.; MARTÍNEZ, C. E.; MENDOZA, R. A.; CHAVEZ, A. E.; ORTIZ, F L. \& QUISPE, S. Á. In vitro study of the antibacterial effect of oleoresin of Copaifera reticulata and the essential oil of Origanum majoricum against Streptococcus mutans and Enterococcus faecalis bacteria of importance in oral pathologies. Int. J. Odontostomat., 12(4):355-361, 2018.

ABSTRACT: The objective of the study was to determine the in vitro antibacterial effect of the oleoresin of Copaifera reticulata (C. reticulata) "copaiba" and of the essential oil of Oreganum majoricum (O. majoricum) "oregano" against Streptococcus mutans (S. mutans) and Enterococcus faecalis (E. faecalis). Sensitivity tests were developed by first activating the bacteria strains to be confronted. The oleoresin of copaiba was diluted with dimethylsulphoside (DMSO), obtaining final concentrations to be tested of $100 \%, 50 \%, 25 \%$, and $12.5 \%$. In relation to the essential oil of oregano, it was only $100 \%$ tested. For the disk agar diffusion test, $100 \mathrm{~mL}$ of each bacterial strain was taken at a turbidity of 0.5 of Mc Farlam, to be planted by dissecting trypticase soy agar plates, and then placing the disks equidistantly loaded with the different concentrations of natural products; $0.12 \%$ chlorhexidine was used as a positive control and DMSO as negative control. The plates were incubated by the candle method in extinction at $37^{\circ} \mathrm{C}$, for a period of 24 hours, after which time the inhibition halos were read. The results obtained by the copaiba, determined an antibacterial effect in its four concentrations, being the biggest halos of inhibition at the concentration of $100 \%$, copaiba genus higher average halos for $S$. mutans of 30.00 $\pm 0.00 \mathrm{~mm}$ and for $E$. faecalis of $8.3 \pm 0.50 \mathrm{~mm}$. In the case of oregano, haloes are produced at a concentration of 100 $\%$ with an average of $25.3 \pm 0.96 \mathrm{~mm}$ for $S$. mutans and for E. faecalis $9.5 \pm 1.29 \mathrm{~mm}$. It is concluded from the study that both copaiba and oregano present an antibacterial effect for both bacteria, being its greater antibacterial effect for both natural products on S. mutans.

KEY WORDS: Antibacterial agent, Enterococcus faecalis, Copaiva, Oreganum, Streptococcus mutans.

\section{REFERENCIAS BIBLIOGRÁFICAS}

Acevedo, D.; Navarro, M. \& Monroy, L. Composición química del aceite escencial de hojas de orégano (Origanum vulgare). Inf. Tecnol., 24(4):43-8, 2013.

Alvares, D. C. \& Alvares Junior, C. A. Endotoxina na endodontia. Rev. Cient. U. F. P. A., 7(1):1-25, 2009.

Arcila-Lozano, C. C.; Loarca-Piña, G.; Lecona-Uribe, S. \& González de Mejía, E. El orégano: propiedades, composición y actividad biológica de sus componentes. Arch. Latinoam. Nutr., 54(1):10011,2004

Arroyo-Acevedo, J.; Quino-Florentini, M.; Martínez-Heredia, J.; Almora-Pinedo, Y.; Alba-González, A. \& CondorhuamánFigueroa, M. Efecto cicatrizante del aceite de Copaifera officinalis (copaiba), en pacientes con úlcera péptica. An. Fac. Med., 72(2):113-7, 2011.

Bandoni, A. L.; Retta, D.; Di Leo Lira, P. M. \& van Baren, C. M. ¿Son realmente útiles los aceites esenciales?. Bol. Latinoam. Caribe Plantas Med. Aromat., 8(5):317-22, 2009.

Bardají, D. K.; da Silva, J. J.; Bianchi, T. C.; de Souza Eugênio, D.; de Oliveira, P. F.; Leandro, L. F.; Rogez, H. L.; Venezianni, R. C.; Ambrosio, S. R.; Tavares, D. C.; Bastos, J. K. \& Martins, C. H. Copaifera reticulata oleoresin: Chemical characterization and antibacterial properties against oral pathogens. Anaerobe, 40:1827,2016

Benbelaïd, F.; Khadir, A.; Abdoune, M. A.; Bendahou, M.; Muselli, A. \& Costa, J. Antimicrobial activity of some essential oils against oral multidrug-resistant Enterococcus faecalis in both planktonic and biofilm state. Asian. Pac. J. Trop. Biomed., 4(6):463-72, 2014.

Burt, S. A. Antibacterial Activity of Essential Oils: Potential Applications in Food. PhD Thesis. Utrecht, Institute for Risk Assessment Sciences, Division of Veterinary Public Health, Utrecht University, 2007.

Dos Santos, A. O.; Ueda-Nakamura, T.; Dias Filho, B. P.; da Veiga Junior, V. F. \& Nakamura, C. V. Copaiba oil: an alternative to development of new drugs against leishmaniasis. Evid. Based Complement. Alternat. Med., 2012:898419, 2012.

Herrero, J. C. Gestión Integrada de los Recursos Forestales en la Amazonia Oriental: Ecología de Dos Especies de Uso Múltiple. Tesis Doctoral. Madrid, Universidad Complutense de Madrid, 2010. 
MOROMI, N. H.; RAMOS, P. D.; VILLAVICENCIO, G. D.; MARTíNEZ, C. E.; MENDOZA, R. A.; CHAVEZ, A. E.; ORTIZ, F L. \& QUISPE, S. Á. Estudio in vitro del efecto antibacteriano de la oleorresina de Copaifera reticulata y el aceite esencial de origanum majoricum frente a Streptococcus mutans y Enterococcus faecalis bacterias de importancia en patologías orales. Int. J. Odontostomat., 12(4):355-361, 2018.

Khan, S. T.; Khan, M.; Ahmad, J.; Wahab, R.; Abb-Elkader, O. H.; Musarrat, J.; Alkhathlan, H. Z. \& Al-Kedhairy, A. A. Thymol and carvacrol induce autolysis, stress, growth inhibition and reduce the biofilm formation by Streptococcus mutans. AMB Express, 7(1):49, 2017.

Koo, H. \& Jeon, J. G. Naturally occurring molecules as alternative therapeutic agents against cariogenic biofilms. Adv. Dent. Res., 21(1):63-8, 2009.

Kunze, B.; Reck, M.; Dötsch, A.; Lemme, A.; Schummer, D.; Irschik H.; Steinmetz, H. \& Wagner-Döbler, I. Damage of Streptococcus mutans biofilms by carolacton, a secondary metabolite from the myxobacterium Sorangium cellulosum. B. M. C. Microbiol., 10:199, 2010.

Leandro, L. M.; Vargas, F. de S.; Barbosa, P. C.; Neves, J. K.; da Silva, J. A. \& da Veiga-Junior, V. F. Chemistry and biological activities of terpenoids from copaiba (Copaifera spp.) oleoresins. Molecules, 17(4):3866-89, 2012.

Lima, S. R.; Junior, V. F.; Christo, H. B.; Pinto, A. C. \& Fernandes, P. D. In vivo and in vitro studies on the anticancer activity of Copaifera multijuga hayne and its fractions. Phytother. Res., 17(9):1048-53, 2003.

Madsen, H. L. \& Bertelsen, G. Spices as antioxidants. Trends Food Sci. Technol., 6(8):271-7, 1995.

Masson, D. S.; Salvador, S. L.; Polizello, A. C. M. \& Frade, M. A. C. Antimicrobial activity of copaíba (Copaifera langsdorffii) oleoresin on bacteria of clinical significance in cutaneous wounds. Rev. Bras. Plantas Med., 15(4 Suppl. 1):664-9, 2013.

Mello da Silveira, S.; Cunha Júnior, A.; Scheuermann, G. N.; Secchi, F. L. \& Vieira, C. R. W. Chemical composition and antimicrobial activity of essential oils from selected herbs cultivated in the South of Brazil against food spoilage and foodborne pathogens. Cienc. Rural, 42(7):1300-6, 2012.

Mendonça, D. E. \& Onofre, S. B. Atividade antimicrobiana do óleoresina produzido pela copaiba - Copaifera multijuga Hayne (Leguminosae). Rev. Bras. Farmacogn., 19(2b):577-81, 2009.

Pacheco, T. A. R. C.; Barata, L. E. S. \& Duarte, M. C. T. Antimicrobial activity of copaiba (Copaifera spp) balsams. Rev. Bras. Plantas Med., 8:123-4, 2006.

Pereyra, E. L. El Futuro de los Productos Andinos en la Región Alta y los Valles Centrales de los Andes/Plantas Medicinales. Estado del Arte del Sector de Plantas Medicinales en Perú. Viena, UNIDO, 2009. Disponible en: http://www.unido.org/fileadmin/ import/69934_PERU_Informe final_plantas medicinales_2vf. pdf

Ramos Perfecto, D. \& Castro Luna, A. Actividad antibacteriana de Copaifera reticulata "Copaiba" sobre Porphyromonas gingivalis aisladas de pacientes con periodontitis. Odontol. Sanmarquina, 17(1):7-11, 2014.

Tavares, A. G. Efeito do Oleo Essencial de Oreganun vulgaris $L$ Oregano o Desenvolvimento de Tolerancia Direta e Cruzada em Cepa de Staphylococcus Aureus Isoladas de Alimentos. Tesis de Maestría en Ciencias de Nutrición. João Pessoa, Universidad Federal de Paraiba, 2014.

Veiga Junior, V. F. \& Pinto, J. A. C. O gênero Copaifera L. Quim. Nova, 25(2):273-86, 2002.

Veiga Junior, V. F.; Rosas, E. C.; Carvalho, M. V.; Henriques M. G. \& Pinto, A. C. Chemical composition and anti-inflammatory activity of copaiba oils from Copaifera cearensis Huber ex Ducke, Copaifera reticulata Ducke and Copaifera multijuga Hayne--a comparative study. J. Ethnopharmacol., 112(2):248-52, 2001.

\author{
Dirección para correspondencia: \\ Mg. Donald Ramos Perfecto \\ Av. German Amezaga 375 \\ Lima \\ PERÚ
}

Email: dramosp@unmsm.edu.pe

Recibido : 09-05-2018

Aceptado : 06-08-2018 